\title{
TRAVEL WRITING SEBAGAI INOVASI PENDIDIKAN PADA NOVEL ETNOGRAFI MANUSIA LANGIT KARYA J.A. SONJAYA
}

\author{
Dina Purnama Sari \\ Akademi Bahasa Asing Bina Sarana Informatika, Jakarta \\ E-mail: dina.dms@bsi.ac.id
}

\begin{abstract}
Abstrak
Penelitian ini bertujuan untuk mendeskripsikan travel writing sebagai inovasi pendidikan pada novel etnografi Manusia Langit karya J.A. Sonjaya. Pembahasannya terkait dengan penelitian antropologi sastra, inovasi pendidikan, dan travel writing. Metode yang digunakan adalah penelitian deskriptif dengan pendekatan strukturalisme serta pendekatan antropologi sastra yang berkaitan dengan unsur instrinsik, travel writing, dan budaya. Objeknya adalah novel etnografi Manusia Langit karya J.A. Sonjaya. Kesimpulannya adalah unsur intrinsik dalam pendekatan strukturalisme berkaitan dengan budaya, khususnya sistem sosial; pendekatan antropologi sosial berkaitan dengan prinsip hidup-mati, harga diri, pesta, dan perempuan, baik dalam persamaan maupun perbedaannya terdapat keterkaitan dari setiap prinsip tersebut; dan travel writing merupakan inovasi pendidikan karena dapat menggugah minat baca, wisata, dan keilmiahan. Hal tersebut dapat dikemas melalui novel.
\end{abstract}

Kata Kunci: etnografi, antropologi sastra, strukturalisme, inovasi pendidikan, travel writing

Abstract

This research aimed to describe the travel writing's as an education innovation on ethnographic novel Manusia Langit by J.A. Sonjaya. This research used the method of descriptive research with structuralism approach and anthropological approach to literature relating to the intrinsic elements, travel writing, and culture. The object is an ethnographic novel Manusia Langit by J. A. Sonjaya. The conclusion is an intrinsic element in the structuralist approach has relation with culture, especially the social system; social anthropology approaches has relation with the principle of life and death, pride, party, and women, both the similarities and differences have linkage of these principles; and travel writing is an educational innovation because it can attract interest in reading, travel, and scientifics. It can be packaged in the novel.

Keywords: ethnographic, anthropological literature, structuralism, academic innovation, travel writing

\section{Pendahuluan}

Penulisan karya ilmiah dapat dilakukan melalui makalah, proposal, laporan, tugas akhir, skripsi, tesis, dan disertasi. Penulisan tersebut dapat dipublikasikan melalui seminar, jurnal, dan sebagainya. Oleh sebab itu, diperlukan metodologi yang benar dan tepat. Penggunaan bahasanya pun ilmiah.

Selain penulisan karya ilmiah, penulis sebagai akademi dapat menulis semiilmiah dan nonilmiah. Berkaitan dengan hal itu, diperlukan persyaratan untuk menguasai penulisan kreatif. Salah satu jenis penulisan kreatif adalah menulis perjalanan atau writing trip. Saat ini, fenomena menulis perjalanan banyak dilakukan oleh para penulis. Writing trip tersebut dilakukan untuk mendapatkan informasi, data, penelitian, atau sekedar menyalurkan hobi. Secara umum, writing trip dilakukan penulis untuk menuangkan hasil perjalanannya ke dalam tulisan, misalnya perjalanan wisata. Setelah penulis melakukan perjalanan wisata dengan mengunjungibeberapa tempat menarik, dia akan menuangkannya ke dalam tulisan. Tulisan tersebut dinamakan writing trip.

Writing trip dapat bersumber dari budaya, bahasa, tempat wisata bersejarah, cenderamata, kesenian, dan hal menarik lainnya. Agar menarik dan pesan penulis mudah dipahami, writing trip dapat ditulis menggunakan rumus jurnalistik $5 \mathrm{~W}+1 \mathrm{H}$ (what, where, who, when, why, dan how). Penyampaian makna dan pesannya dapat menggunakan teknik deskriptif, naratif, argumentatif, eksposisi, persuasi, atau campuran. 
Writing trip dapat diungkapkan tak hanya melalui rumus jurnalistik $5 \mathrm{~W}+1 \mathrm{H}$, namun juga dapat ditulis dengan menggunakan unsur intrinsik sastra. Unsur intrinsik sastra terdapat dalam cerpen dan novel. Salah satu novel yang mengungkapkan writing tripadalah Manusia Langit karya J.A. Sonjaya. Manusia Langit merupakan novel etnografi yang mengungkapkan kultur Nias yang eksotis dengan panduan antara fakta dan fiksi. Dengan demikian, writing trip dilakukan sebagai inovasi pendidikan dalam penyampaian makna atau pesan yang ingin disampaikan oleh penulis kepada pembacanya. Berkaitan dengan hal tersebut, peneliti tertarik untuk mengambil judul "Travel Writing sebagai Inovasi Pendidikan pada Novel Etnografi Manusia Langit Karya J.A. Sonjaya".

Berdasarkan latar belakang masalah tersebut, penyusun hanya membatasi masalah pada travel writing sebagai inovasi pendidikan pada novel etnografi Manusia Langit karya J.A. Sonjaya. Adapun pembahasannya terkait dengan penelitian antropologi sastra, inovasi pendidikan, dan travel writing.

\section{Strukturalisme, Antropologi Sastra, dan Travel Writing}

Untuk menjelaskan permasalahan di atas digunakan tiga konsep, yakni strukturalisme, antropologi sastra, dan travel writing. Menurut Junus (Suwardi Endraswara, 2003: 49), strukturalisme dipahami sebagai bentuk karya sastra dan sekadar formalisme modern. Sementara Menurut Jean Peaget (Suwardi Endraswara, 2003: 50), strukturalisme mengandung tiga hal pokok, yaitu gagasan keseluruhan (wholeness), gagasan transformasi (transformation), dan gagasan keteraturan yang mandiri (self regulation). Suwardi Endraswara (2003: 50) menyatakan bahwa karya sastra dibangun atas dasar bahasa, memiliki ciri bentuk (form) dan isi (content) atau makna (significance) yang otonom. Artinya, pemahaman karya sastra dapat diteliti dari teks sastra itu sendiri.

Burhan Nurgiyantoro (2001: 36-37) menyatakan strukturalisme dapat dipandang sebagai salah satu pendekatan (baca: penelitian) kesastraan yang menekankan pada kajian hubungan antarunsur pembangun karya yang bersangkutan. Dengan demikian, strukturalisme adalah salah satu pendekatan sastra yang dilakukan untuk mengidentifikasi, mengkaji, dan mendeskripsikan fungsi serta hubungan antarunsurnya dengan tujuan menyumbangkan estetika dan makna keseluruhan yang ingin dicapai.

Berdasarkan uraian tersebut, dapat disimpulkan bahwa strukturalisme adalah salah satu pendekatan yang mengkaji dan mendeskripsikan karya sastra antarunsurnya dalam karya sastra. Unsur tersebut terdiri dari tema, amanat, plot atau alur, penokohan, latar, dan sudut pandang.

Sementara itu, antropologi sastra menurut Nyoman Kutha Ratna (2011, 9-10) berkaitan dengan analisis terhadap karya sastra dengan mempertimbangkan aspek-aspek, unsurunsur, kaitan antarunsur, dan sudut pandang antropologisnya. Akan tetapi, pertimbangan tersebut bukanlah prioritas. Hal yang menjadi prioritas dalam pendekatan antropologi sastra adalah dominasi sastra itu sendiri. Dominasi sastra dikaitkan dengan aspek-aspek, unsurunsur, kaitan antarunsur dan sudut pandang antropologisnya. Dengan demikian, analisis aspek pendekatan antropologi sastra dapat dibedakan atas dua hal, yaitu analisis aspek antropologis yang terkandung dalam karya dan aspek yang terjadi dalam masyarakat tetapi berpengaruh terhadap karya sastra.

$$
\text { Nyoman Kutha Ratna (2011: 247) }
$$
menyatakan etnografi adalah tulisan yang dengan atau tanpa ke lapangan pembaca sudah dapat memahami objek secara intens. Berkaitan dengan pemahaman novel dan etnografi tersebut, Nyoman Kutha Ratna (2011: 244) mengungkapkan bahwa secara genetis karya sastra memiliki kaitan erat dengan etnografi. Keduanya memanfaatkan suatu cerita yang diperoleh melalui lokasi tertentu, diadopsi oleh 
seorang penulis ke dalam suatu bentuk tertentu.

Lebih lanjut, Nyoman Kutha Ratna (2011:

245) menyatakan dengan alasan tertentu karya para orientalis, sebagai etnografi dapat berubah menjadi sebuah novel. Selain itu, Nyoman Kutha Ratna (2011: 248) menyatakan antropologi sastra membicarakan manusia dan kebudayaan, maka semua genre, baik sastra lama maupun modern juga karya-karya yang dikategorikan sebagai postmodern, dapat dianalisis melalui antropologi sastra. Perbedaannya hanya terlihat dari segi kuantitas penyajiannya.

Suwardi Endraswara menyatakan bahwa penelitian antropologi sastra dapat menitikberatkan kepada dua hal. Pertama meneliti tulisan-tulisan etnografi yang berbau sastra untuk melihat estetikanya. Kedua meneliti karya sastra dari sisi pandang etnografi, yaitu untuk melihat aspek-aspek budaya masyarakat.

Menurut Bernard (Suwardi Endraswara, 2003: 109), pada umumnya penelitian antropologi sastra lebih bersumber kepada tiga hal, yaitu manusia/orang, artikel tentang sastra, dan bibliografi. Ketiga sumber data tersebut dapat dipandang sebagai documentation resource karena karya sastra merupakan sumber informasi.

Nyoman Kutha Ratna (2011: 248) menyatakan bahwa analisis antropologi sastra pada umumnya dilakukan melalui dua cara, yaitu, pertama, bahasa dengan mendeskripsikan terlebih dahulu unsur-unsurnya kemudian dilanjutkan dengan analisis secara antropologis, dan kedua, secara langsung mendeskripsikan melalui analisis antropologi sastra sesuai dengan tujuan penelitian. Dalam perkembangan selanjutnya yang dianggap lebih baik adalah cara yang kedua.

Berdasarkan uraian di atas, dapat disimpulkan bahwa antropologi sastra adalah karya sastra yang berkaitan dengan antropologi, khususnya etnografi. Etnografi berkaitan dengan budaya masyarakat dan dapat dikaitkan dengan estetika sastra. Salah satu contoh karya sastra yang dapat diteliti dengan ruang lingkup antropologi sastra adalah novel etnografi. Novel etnografi merupakan sastra modern. Sebagai bentuk modern, novel etnografi berkaitan dengan manusia dan kebudayaannya. Cakupannya cukup luas dan beragam sehingga pembahasan terkait dengan hal tersebut akan lebih dalam, luas, dan kaya.

Konsep ketiga yang digunakan dalam penelitian ini adalah travel writing. Menurut Tim Youngs dalam (Grzegoz Moroz: tanpa tahun: 20), "Travel writing feeds from and back into other forms of literature. To try to identify boundaries between various forms would be impossible and I would be deeply suspicious of any attempt at the task.".

Pendapat lain dikemukakan oleh Jonathan Rabat (Grzegoz Moroz: tanpa tahun: 22), "as a literary form, travel writing is a notoriously raffish open house where different genres are likely to end up in the same bed. It accommodates the private diary, the essay, the short story, the prose poem, the rough note, and polished table talk within discriminate hospitality. It freely mixes narrative and discursive writing".

Seperti yang diungkapkan juga oleh Holland and Huggan's book (Grzegoz Moroz, tanpa tahun: 24), "it introduces a novel and thought provoking treatment of issues connected with travel books and travel writing, such as the fiction/ non-fiction boundary and the construction of a narrative persona".

Jan Borm (Grzegoz Moroz, tanpa tahun: 24) menyatakan " 'travel writing' is not a genre but a variety of texts, both predominantly fictional and nonfictional, whose main theme is travel. He postulated that the terms "literature of travel" and "travel literature" because of the "literary" element at work in all of these categories, should be treated as synonyms of "travel writing".

Dengan demikian, berdasarkan pendapat para ahli tersebut, dapat disimpulkan bahwa travel writing adalah salah satu jenis keterampilan menulis yang berkaitan dengan penulisan kreatif, baik fiksi maupun nonfiksi. Jika diungkapkan dalam fiksi, maka di dalamnya mengisahkan fakta melalui fiksi dengan konstruksi naratif sang penulis, misalnya cerpen dan novel. Akan 
tetapi, jika diungkapkan melalui nonfiksi, maka data, fakta, dokumen, dan hasil perjalanan diungkapkan dengan konstruksi deskriptif, argumentasi, eksposisi, persuasi, ataupun campuran sang penulis. Contohnya, artikel, opini, dan feature.

Sesuai dengan pertanyaan permasalahan yang dipaparkan di atas mengenai bagaimana inovasi pendidikan dalam novel etnografi Manusia Langitkarya J.A. Sonjaya perlu dijelaskan pengertian inovasi pendidikan. Sullivan O (2008: 3) menyatakan "innovation is the process of making changes to something established by introducing something new". Oleh karena itu, Sullivan berpendapat bahwa inovasi dapat dilakukan di berbagai bidang dan ilmu. Berdasarkan hal tersebut, Sullivan O (2008: 6) menyatakan bahwa konsep inovasi berkaitan dengan invention, growth, creativity, design, exploitation, change, failure, entrepreneurship, customers, knowledge, dan society.

Sullivan O (2008: 4) menyimpulkan dua hal terkait dengan definisi inovasi, yaitu 1) "innovation is the process of making changes to something established by introducing something new that adds value to customers, dan 2) innovation is the process of making changes to something established by introducing something new that adds value to customers and contributes to the knowledge store of the organization”.

Salah satu definisi inovasi dinyatakan dalam kamus The New Oxford Dictionary of English (Sullivan O, 2008: 4) menyatakan bahwa inovasi adalah making changes to something established by introducing something new.

Jika dikaitkan dengan inovasi pendidikan, Michael Fullan (Andy Hockley, 2009: 176) menyimpulkan beberapa hal terkait dengan kegagalan dan keberhasilan yang dinamakan "educational reform". Educational reform tersebut terjadi karena kegagalan yang dilatarbelakangi oleh lima alasan, yaitu 1) believing that complex problems can be solved quickly; 2) adopting innovations which have only symbolic benefit; 3) responding too quickly to fads and fashions; 4) misunderstanding resistance as an attempt to block, rather than as indicating a need for help and support; dan 5) allowing pockets of success to fail through lack of support.

Dengan demikian, inovasi pendidikan adalah proses pengubahan pendidikan kepada hal yang baru untuk kepuasan pelanggan dan memenangkan kompetisi. Untuk mencapainya diperlukan adanya pertumbuhan, penemuan atau penciptaan baru, eksploitasi positif, berjiwa wirausaha, kreativitas, desain, dan pengetahuan. Selain itu, keikutsertaan lingkungan sekitar dan pelanggan dapat membantu tercapainya hasil yang diinginkan oleh organisasi pendidikan itu sendiri.

Metode yang digunakan adalah penelitian deskriptif dengan pendekatan strukturalisme serta pendekatan antropologi sastra yang berkaitan dengan unsur instrinsik, travel writing, dan budaya. Objeknya adalah novel etnografi Manusia Langit karya J.A. Sonjaya. Suharsimi Arikunto (20013: 310) menyatakan bahwa metode penelitian deskriptif tidak dimaksudkan untuk menguji hipotesis tertentu, tetapi hanya menggambarkan "apa adanya" tentang suatu variabel, gejala atau keadaan. Dengan kata lain, secara umum penelitian deskriptif tidak dimaksudkan untuk menguji hipotesis. Dengan demikian, pembahasan di dalam penelitian ini mengaitkan antara fakta dan fiksi di dalam novel etnografi Manusia Langit karya J.A. Sonjaya dengan travel writing sebagai inovasi pendidikan.

\section{Travel Writing dalam Novel Etnografi Manusia Langit Karya J.A. Sonjaya}

Untuk membahas novel etnografi Manusia Langit secara lebih jelas akan dipaparkan terlebih dahulu ringkasan ceritanya. Tokoh utama novel ini adalah Mahendra. Ia merupakan dosen yang merangkap arkeolog di sebuah universitas di Yogyakarta. Ia pergi ke Banuaha, sebuah kampung pedalaman Pulau Nias. Di Banuaha, Mahendra berusaha melepaskan diri dari kungkungan peradaban kampus dan berusaha menjadi bagian dari suku di sana. Penduduk asli Banuaha menganggap bahwa pulau tersebut 
merupakan tempat turunnya manusia dari langit.

Mahendra belajar banyak hal di Banuaha, seperti periuk bayi, harga diri, langit dan bumi, pesta, maskawin, perempuan dan babi, serta mati dan hidup. Hal-hal tersebut merupakan prinsip perbedaan dan persamaan antara dunia kampus di Yogyakarta dan dunia orang Nias di Banuaha.

Kehadiran Saita, gadis Nias yang sudah dibeli pemuda kampung tetangga membuat Mahendra gundah. Kegundahan Mahendra terbayar mahal karena dia memutuskan untuk meninggalkan Banuaha dan kembali ke Yogyakarta. Kegundahan sebelumnya pernah dialami oleh Mahendra saat mendengar kabar bahwa Yasmin, gadis asal Lombok, mahasiswinya meninggal dunia beserta bayi yang dikandungnya. Bayi tersebut merupakan hasil hubungan asmara Mahendra dengan Yasmin. Pada akhirnya, Saita meninggal dunia dengan menggantung dirinya dan Mahendra akhirnya sadar bahwa dia merupakan manusia langit seperti halnya orang Nias di Banuaha. Sayangnya, Yasmin dan anaknya tak sempat bertemu dengan Mahendra karena pria tersebut tewas akibat kecelakaan kapal.

Melalui pendekatan strukturalisme diketahui bahwa novel etnografi Manusia Langit adalah tentang persamaan dan perbedaan kampus di Yogyakarta dan suku Nias di Banuaha. Kedua hal tersebut dikaitkan dengan harga diri, prinsip hidup-mati, pesta, dan perempuan. Tema tambahannya terdiri dari kisah kasih Yasmin dengan Mahendra, kisah kasih Mahendra dengan Saita, persahabatan dan kekerabatan.

Amanat yang disampaikan penulis berkaitan dengan kearifan lokal, yaitu, dengan kehadiran perkembangan di lingkungan sekitar kadang membingungkan penduduk asli dengan hal tersebut sehingga terjadi benturan antara budaya lama dengan budaya baru. Selain itu, diperlukan kebijakan menyikapi perbedaan di lingkungan baru. Perbedaan tersebut berkaitan dengan adat-istiadat di lingkungan baru.

Secaraumum, plotataualuryangdigunakan adalah alur maju. Kisah dibuka dengan prolog Jasmine yang mengajak Rayas untuk napak tilas perjalanan Mahendra. Kemudian alur sempat mundur dengan mengisahkan periuk bayi yang ditemukan oleh Mahendra di Banuaha. Alur pun mundur kembali menceritakan kisah kasih antara Mahendra dengan Yasmine. Hubungan mereka yang diterima oleh kedua orang tua Yasmine tak menyurutkan langkah Mahendra untuk menerima mahasiswanya itu sebagai pendamping hidup. Alur melaju mengisahkan Mahendra yangmelepaskan diridarikungkungan peradaban kampus di Yogyakarta. Ia kabur ke Banuaha, sebuah kampung di pedalaman Pulau Nias setelah sebelumnya sempat menjadi relawan di tempat lain. Di Banuaha, Mahendra belajar banyak hal mengenai adat-istiadat di Banuaha. Dia juga gundah ketika mengetahui bahwa Saita, gadis Nias, yang disukainya telah dibeli pemuda kampung tetangga. Pemuda tersebut merupakan bagian dari keluarga Pak Nai Laiya yang bersiteru dengan keluarga Ama dan Ina Budi. Kisah ditutup dengan kepergian Mahendra yang meninggal di lautan. Saat itu, Mahendra mengalami kecelakaan kapal. Fiqoh, salah seorang mahasiswi yang diselamatkan oleh Mahendra berhasil bertemu dengan Yasmine dan mengabarkan bahwa Mahendra telah meninggal dunia. Bersama Fiqoh, Yasmine dan Rayas melakukan napak tilas perjalanan yang dilakukan oleh Mahendra di Banuaha. Berkat bantuan teman-teman relawan Fiqoh, Yasmine dan Rayas segera menemui Ama Budi yang telah berjasa kepada Mahendra.

Yasmine, Rayas, Mahendra, Ama Budi, Ina Budi, Sayani, Budi, Pak Nai Laiya, Saita, Amöli, Pak Lektor, Arofösi Laiya, dan Rudi merupakan beberapa tokoh yang disebutkan oleh penulis di dalam novel etnografi Manusia Langit. Tokoh-tokoh tersebut hadir mewarnai perjalanan hidup tokoh utama, Mahendra. Mahendra mengalami kegundahan cinta dengan Yasmine dan Saita. Mahendra belajar 
kekerabatan dan kearifan lokal dari Ama Budi, Ina Budi, Gadis Gunung yang berusia 27 tahun dan menikah dengan Ama Budi sepeninggalnya Ina Budi, Pak Letor, Sayani, dan Budi. Mahendra pun mendapatkan nama Mahendra Hia. Akan tetapi, nama "Hia" belum layak diperoleh secara resmi karena Mahendra belum mengadakan pesta pengukuhan anak angkat. Jika pesta tersebut telah diselenggarakan, maka Mahendra pun resmi menjadi anak angkat Ama Budi dan menyandang nama Hia. Berkat bantuan Ama Budi dan Pak Lektor, Mahendra dapat bekerja sebagai guru di Banuaha. Dari Pak Nai Laiya, Amöli, dan Arofösi Laiya, Mahendra belajar adat-istiadat mengenai harga diri.

Karakteristik tokoh bijaksana, cenderung putih, dan protagonis didominasi oleh Ama Budi dan Ina Budi. Keduanya digambarkan sebagai sepasang suami istri yang akur, bijaksana, dan mematuhi adat. Penggambaran keduanya dijelaskan kala Ina Budi melarang Mahendra membantu pekerjaan rumah tangga dan beberapa penjelasan yang diberikan Ama Budi kepada Mahendra dalam situasi yang berbeda mengenai mas kawin laki-laki dengan perempuan di Banuaha, perhitungan adat untuk upacara, dan sebagainya. Adapun tokoh yang cenderung hitam, gelap, dan antagonis adalah Pak Nai Laiya, Amöli, dan Arofösi Laiya. Ketiganya merupakan satu keluarga yang mendendam dengan keluarga Ama Budi. Hal itu karena kesalahan orang tua mereka sebelumnya.

Latar tempat pada novel etnografi Manusia Langit terdapat di Yogyakarta, Banuahapedalaman Pulau Nias, alam pegunungan Hilinata, Gunung Sibolga, Laut Sibolga, dan Sitoli. Latar suasana lebih menggambarkan kegembiraan karena mendapatkan kerabat baru, ilmu baru, pengalaman di masa lalu, dan kisah mengenai budaya di Banuaha serta di Yogyakarta. Adapun untuk latar waktu digambarkan dengan baik, salah satunya, "Matahari mulai meninggi. Baru beberapa hari ini di Banuaha cerah karena biasanya hujan selalu datang meski pada musim kemarau sekalipun". (J.A. Sonjaya, 2010: 66)".

Sudut pandang (point of view) yang digunakan oleh penulis adalah sudut pandang orang pertama, yaitu "aku". Dalam kisah "aku”, sang penulis seolah berpikir dan bertingkah laku seperti Mahendra, sang tokoh utama. Tokoh utama yang semula dosen, arkeolog, relawan, kemudian menjadi guru. Pemilihan gaya "aku" lebih memudahkan bagi penulisnya untuk mengungkapkan pikiran dan gagasannya ke dalam tulisan. Dengan demikian, pembaca seolah diberikan gambaran yang jelas dan nyata mengenai budaya, perasaan, dan pemikiran sang tokoh. Pembaca juga seolah disuguhi eksotika kultur Nias. Hal lain terkait dengan pemilihan sudut pandang adalah sang penulis tanpa disadarinya telah membawa pembaca untuk berkunjung ke Yogyakarta, Nias, Sibolga, dan Sitoli. Dengan demikian, pembaca disuguhi gambaran keindahan alam di Nias, Sibolga, dan Sitoli serta kebudayaan di Yogyakarta yang ternyata tidak seperti yang pernah dialami oleh Mahendra.

Semantara itu, berdasarkan pendekatan antropologi sastra akan dianalisis aspek-aspek yang berkaitan dengan masyarakat, tetapi yang berpengaruh terhadap karya sastra. Analisis ini melihat unsur instrinsik karya sastra. Hal itu karena antropologi sastra mengimplikasikan peran sastra untuk mengevokasi keberagaman budaya. Keberagaman budaya yang dianalisis adalah budaya Jawa dan budaya Buanaha di pedalaman Pulau Nias. Keberagaman tersebut dapat terdiri dari perbedaan dan persamaan. Keberagamannnya menyangkut prinsip hidupmati, harga diri, pesta, dan perempuan.

Dalam penggambaran hidup mati terdapat perbedaan dari asal-usul manusia di Banuaha. Suku di Banuaha percaya bahwa mereka berasal dari Manusia Langit sedangkan Mahendra percaya bahwa mereka berasal dari Melayu Muda. Hal ini terkait dengan temuan batu-batu megalit dan ciri-ciri yang disebutkan oleh Ama Budi. Selain itu, kedatangan Melayu 
Muda ke Nusantara untuk menggeser manusia yang sudah menetap sebelumnya, Suku Belada. Perbedaan lainnya adalah suku di Banuaha percaya bahwa anak muda diibaratkan sebagai elang. Walaupun sulit dipahami, Mahendra setuju dengan penjelasan yang diberikan oleh Ama Budi. Persamaannya adalah cara penguburan jenazah yang dikebumikan dengan tanah. Jenazah suku Banuaha tidak lagi dibiarkan di depan rumah dan yang lain membiarkannya selama berbulan-bulan hingga dagingnya luruh dan tersisa tulang belulangnya. Kemudian, tulang belulang tersebut ditaruh di atas piring dan diletakkan di bawah awina (dolmen).

Harga diri digambarkan melalui periuk bayi yang ditemukan oleh Mahendra saat menggali di Banuaha. Selain itu, harga yang harus dibayar Mahendra mahal oleh dirinya sendiri sebagai seorang dosen; prinsip Budi, kakak Sayani yang kawin lari ke Padang karena perbedaan pemikiran dengan adat di Banuaha; Sayani dihargai dan dihormati oleh para pemabuk di Pasar Gromo karena dia keturunan keluarga Hia sebagai marga yang dianggap paling tua di Nias; harga permintaan maaf yang diberikan oleh seseorang atas perbuatannya yang menyakiti atau dianggap melanggar adat; harga seorang guru yang tinggi karena profesi guru sangat dihormati di kampung.

Harga diri merupakan dua kata yang saling berkaitan. Harga diri yang berada dalam budaya di Banuaha secara tidak langsung dirasakan oleh Mahendra. Sebagai seorang dosen, dia pergi dari kehidupan kampus karena merasa tak mampu menerapkan nilai-nilai budaya kampus. Budi, kakak Sayani, pergi dari Banuaha karena tidak sependapat dengan budaya di sana, khususnya mengenai pernikahan. Budi yang sejak kecil dididik di gereja dan sangat taat beragama tidak membayar mas kawin sesuai adat. Budi mengikuti aturan gereja untuk mas kawin. Hal itulah yang menyebabkan dia kawin lari dengan istrinya ke Padang dan kembali bersama istri dan anaknya untuk menghadiri pemakaman ibunya. Usai pemakaman, Budi beserta istrinya kembali ke Padang. Akan tetapi, Budi berjanji akan kembali ke Banuaha ketika ilmu agamanya mencukupi untuk memberikan pencerahan di Banuaha. Saat dia kembali, Ama Budi menerimanya dengan upacara adat sederhana setelah sebelumnya memutuskan hubungan dengan anak pertamanya itu.

Ketika orang Nias memiliki anak pertama, maka kedua orangtuanya dipanggil nama anak pertamanya. Oleh karena Budi anak pertama, maka kedua orangtuanya dipanggil Ama Budi dan Ina Budi. Walaupun Budi kawin lari dan meninggalkan Banuaha, Ama dan Ina tetap dipanggil dengan tambahan nama anak pertama mereka, Budi. Hal ini disebabkan oleh rasa sayang kedua orangtuanya itu.

Harga diri seseorang di Banuaha juga berkaitan dengan marga keluarga yang dimilikinya. Hal ini tercermin dari marga yang dimiliki oleh Sayani, Hia. Para pemabuk tidak berani dengan Sayani yang bermarga Hia karena marga keluarganya dianggap sebagai marga tertua di Nias.

Permintaan maaf yang dilakukan oleh diri sendiri kepada pihak lain merupakan hal yang luar biasa. Hal ini salah satunya dialami oleh Mahendra saat melakukan penggalian di tanah milik Amöli. Penggalian itu berkaitan dengan periuk bayi. Amöli tidak sependapat dengan Mahendra yang menyatakan bahwa periuk bayi itu ada bukan karena roh-roh jahat memakan bayi-bayi di kampung mereka melainkan keputusasaan mereka yang menyebabkan mereka mati. Informasi periuk bayi diperoleh Amöli dari Sayani yang disampaikannya tanpa memberitahu Mahendra terlebih dahulu. Untuk menyelamatkan Sayani, Mahendra berbohong dengan menyatakan bahwa benda tersebut bukanlah periuk bayi melainkan sisa dapur zaman dahulu. Sayani pun membela Mahendra. Sayangnya, untuk menyelamatkan harga diri, permintaan maaf tak cukup dilakukan Mahendra. Mahendra dan Sayani membayar denda dengan memberikan babi kepada Amöli.

Hal lainnya berkaitan dengan harga diri 
adalah profesi guru yang sangat dihormati karena tak mudah untuk menjadi guru di Banuaha. Guru dianggap sebagai orang yang cerdas dan berpengetahuan luas. Contohnya, Ama Firma, guru senior SMP di Banuaha, hadir memberikan kesepakatan perdamaian antara Mahendra dan Sayani dengan Amöli berkaitan dengan periuk bayi.

Pesta di dalam budaya di Banuaha terdiri dari beberapa pesta, salah satunya adalah Mangowasa. Mangowasa merupakan pesta yang dilakukan untuk mendapatkan pengakuan sebagai bangsawan dan suara sebagai kepala desa yang didengar oleh masyarakat sekitar. Mangowasa diselenggarakan dengan mengorbankan ratusan ekor babi, puluhan gram emas, dan berkarung-karung beras untuk menjamu khalayak yang datang ke pesta selama tujuh hari tujuh malam. Pesta tersebut dapat dibantu oleh pinjaman keluarga dan kerabat.

Pesta Mangowasa pernah dilakukan oleh Ama Budi. Usai pesta tersebut, Ama Budi mendapat gelar Barasi Awuwukha. Jika ada Ono Banuaha yang menyelenggarakan pesta, maka Ama Budi mendapatkan bagian daging babi yang paling banyak termasuk kepala babi. Kepala babi merupakan penghargaan tertinggi. Selain itu, pendapat Ama Budi pun didengar oleh masyarakat sekitar. Akan tetapi, di sisi lain, Ama Budi berhutang hingga saat ini. Sejak pesta Mangowasa tahun 1985 hingga saat ini belum ada seorang Banuaha yang mengorbankan babi sejumlah yang dikorbankan oleh Ama Budi. Hal itu karena orang Banuaha beranggapan bahwa pesta adat hanya membuat diri menjadi miskin. Pendapat tersebut diberikan oleh orang yang meletakkan harta di atas harga diri. Jadi, gelar Barasi Awuwukha tidak dapat dipergunakan untuk mencari nafkah dan makan, kecuali saat pesta. Dengan demikian, hidup keluarga Ama Budi termasuk miskin dibandingkan dengan yang lainnya di kampung. Akan tetapi, di sisi lain, dia dihargai sebagai ketua adat.

Di dalam kehidupan modern, Pesta Mangowasa sama seperti wisuda, pengukuhan doktor, dan pencalonan anggota legislatif. Saat wisuda, wisudawan menghadiri wisuda dengan ditemani oleh keluarga, sahabat dekat, dan kerabat dekat. Selain itu, ketok palu, memakai topi wisuda, dan membayar sejumlah uang untuk keperluan wisuda. Seorang doktor juga menyiapkan pidato, sang penguji mengetuk palu untuk mengukuhkan statusnya, serta dia menjamu para tamunya dengan menyediakan makan dan minum. Adapun untuk pencalonan anggota legislatif diperlukan biaya yang cukup besar.

Perempuan Banuaha merupakan harta berharga di dalam keluarga. Hal ini karena mas kawin yang lumayan besar yang harus diberikan oleh pihak pengantin laki-laki kepada perempuan. Sayangnya, mas kawin tersebut tidak dinikmati oleh sang perempuan karena diberikan kepada keluarga dan kerabat perempuan. Selain itu, usai upacara pernikahan, sang perempuan mengabdi kepada suaminya, yakni dengan mengurus anak, pekerjaan rumah tangga, dan melayani sang suami dengan sebaikbaiknya. Hal inilah yang akan dialami oleh Saita, perempuan yang disukai oleh Mahendra. Sayangnya, Saita, gadis Nias itu ternyata sudah dibeli pemuda kampung tetangga yang masih kerabat dengan Pak Nai Laiya. Hal inilah yang membuat Mahendra gundah kemudian memutuskan untuk tidak melamar Saita karena uang yang dimilikinya tak cukup untuk menikahi Saita.

Hal lainnya terkait dengan perempuan Nias adalah seorang laki-laki tak boleh menatap dada perempuan Nias dengan tatapan penuh birahi. Jika diketahui laki-laki tersebut menatap dada perempuan dengan penuh birahi, maka akan dikenai denda. Denda tersebut merupakan kontrol positif sosial yang berbeda dengan di kota.

Dengan demikian, prinsip-prinsiptersebut dilakukan sesuai dengan tataran budaya yang berlaku di Banuaha. Di sisi lain, tataran tersebut memiliki pelindung bagi perempuan, harga diri, harta, kekerabatan, dan lainnya. Namun di sisi 
lain, tataran tersebut memiliki kekurangan, yaitu dapat menjadi beban tersendiri bagi masyarakat yang berada di dalamnya.

Pada hakikatnya, pendidikan dilakukan untuk memperbaiki kehidupan seseorang atau sekelompok orang agar menjadi lebih baik dari sebelumnya. Untuk itulah inovasi diperlukan agar pendidikan dapat tercapai, salah satunya melalui travel writing. Travel writing dapat dituliskan dalam bentuk novel. Penyajiannya berupa fakta dan fiksi. Salah satu novel yang mengungkapkan hal tersebut adalah novel etnografi Manusia Langit karya J.A Sonjaya. Di dalamnyamdibahas mengenai fakta-fakta terkait etnografi di Banuaha, pedalaman Pulau Nias, temuan Periuk Bayi dan Dolmen dan sistem sosial yang berkaitan dengan prinsip hidup-mati, harga diri, pesta, dan perempuan.

Temuan Periuk bayi dan dolmen merupakan artefak berharga yang dapat dilestarikan kemudian diteliti. Sistem sosial tersebut dapat dikaji secara sosiologi, psikologi, maupun antropologi kemudian dapat dikaji melalui sastra.

Novel ini dapat dijadikan masukan dan kritik bagi pemerintah berkaitan dengan pemilihan calon legislatif dan kurangnya tenaga guru di pedalaman Indonesia. Selain itu, tidak mudah menyamaratakan kemampuan pendidikan di setiap wilayah di Indonesia. Dengan demikian, dapat disimpulkan bahwa travel writing merupakan media efektif dalam penyampaian informasi kepada masyarakat dan pemerintah.

\section{Kesimpulan}

Ditinjau dari pendekatan strukturalisme, diketahui bahwa karya mengandung unsur intrinsik yang berkaitan dengan budaya, khususnya sistem sosial. Dengan demikian, berdasarkan hasil pembahasan dan analisis mengenai pendekatan antropologi sosial terkait dengan prinsip hidup-mati, harga diri, pesta, dan perempuan, baik persamaan maupun perbedaannya adalah terdapat keterkaitan dari setiap prinsip tersebut. Dengan adanya prinsip yang dikontrol dengan baik, maka diharapkan terjadi budaya yang beradab. Travel writing merupakan inovasi pendidikan karena dapat menggugah minat baca, wisata, dan keilmiahan. Hal tersebut dapat dikemas melalui novel.

\section{Daftar Pustaka}

Arikunto, Suharsimi. 2003. Manajemen Penelitian. Edisi Baru. Jakarta: Rineka Cipta.

Endraswara, Suwardi. 2013. Metodologi Penelitian Sastra. Epistemologi, Model, Teori, dan Aplikasi. Yogyakarya: Pustaka Widyatama.

Moroz, Grzegoz. Tanpa Tahun. Travellers, Novelist, and Gentlemen. Constructing Male Narrative in British Travel Books, from the Beginnings to the Second World War. Peter Lang Edition.

Nurgiyantoro. Burhan. 2002. Teori Pengkajian Fiksi. Yogyakarta: Gadjah Mada University Press.

Ratna, Nyoman Kutha. 2011. Antropologi Sastra. Peranan Unsur-unsur Kebudayaan dalam Proses Kreatif. Yogyakarta: Pustaka Pelajar.

Sonjaya, J.A. 2010. Novel Etnografi Manusia Langit. Jakarta: Kompas.

Sullivan, O. Defining Innovation Chapter 1. 5/29/2008.

Warren, Jhon W. 2009. The International Journal of The Book. Volume 6, Number1. International and Future of the E-book. Melbourne: Common Group Publishing.

\section{Sumber Internet}

Anonim. "BAB III". dalam http://eprints. undip.ac.id/42644/3/BAB_III.pdf (diunduh pada Sabtu, 28 Maret 2015).

Hockley, Andy. 2009. Managing Innovation in Educational Organization. Romania. www. hoxerix.ro (diunduh pada Sabtu, 28 Maret 2015). 